University of Nebraska - Lincoln

DigitalCommons@University of Nebraska - Lincoln

$12-2011$

\title{
Evaluating the Cost-Effectiveness of Roadside Culvert Treatments
}

Francisco Daniel B. de Albuquerque

University of Nebraska-Lincoln, dbenicio@huskers.unl.edu

Dean L. Sicking

University of Nebraska - Lincoln, dsicking1@unl.edu

Ronald K. Faller

University of Nebraska - Lincoln, rfaller1@unl.edu

Karla A. Lechtenberg

University of Nebraska - Lincoln, kpolivka2@unl.edu

Follow this and additional works at: https://digitalcommons.unl.edu/civilengfacpub

Part of the Civil Engineering Commons

de Albuquerque, Francisco Daniel B.; Sicking, Dean L.; Faller, Ronald K.; and Lechtenberg, Karla A., "Evaluating the Cost-Effectiveness of Roadside Culvert Treatments" (2011). Civil Engineering Faculty Publications. 46.

https://digitalcommons.unl.edu/civilengfacpub/46

This Article is brought to you for free and open access by the Civil Engineering at DigitalCommons@University of Nebraska - Lincoln. It has been accepted for inclusion in Civil Engineering Faculty Publications by an authorized administrator of DigitalCommons@University of Nebraska - Lincoln. 


\title{
Evaluating the Cost-Effectiveness of Roadside Culvert Treatments
}

\author{
Francisco Daniel B. de Albuquerque, Ph.D., ${ }^{1}$ Dean L. Sicking, Ph.D., P.E., ${ }^{2}$ \\ Ronald K. Faller, Ph.D., P.E., ${ }^{3}$ and Karla A. Lechtenberg, M.S.M.E., EाT ${ }^{4}$
}

1. Post-Doctoral Research Associate, University of Nebraska-Lincoln, 130H Whittier Bldg., Lincoln, NE 68583-0853;

Corresponding author: email dbenicio@huskers.unl.edu

2. Professor, and MwRSF Director, University of Nebraska-Lincoln, 130N Whittier Bldg., Lincoln, NE 68583-0853; email dsicking@unl.edu

3. Research Assistant Professor, University of Nebraska-Lincoln, 130R Whittier Bldg., Lincoln, NE 68583-0853; email rfaller1@unl.edu

4. Research Associate Engineer, University of Nebraska-Lincoln, 130G Whittier Bldg., Lincoln, NE 68583-0853; email Kpolivka2@unl.edu

\begin{abstract}
Roadside cross-drainage culverts have been found to affect vehicle accident injury levels. As a result, highway designers have commonly used three safety treatments to protect errant motorists from striking culvert openings. These safety treatments have included: culvert extension, guardrail installation, and the application of safety grating. However, the identification of the most appropriate safety treatment for roadside culverts may be challenging; accident costs may dramatically change under different road and traffic characteristics. The purpose of this study was to estimate accident costs for a wide range of road and traffic scenarios and then define the safest treatment (i.e., treatment with lowest accident cost) for a variety of traffic, roadway, and roadside characteristics. Over 3,000 highway scenarios were modeled using the Roadside Safety Analysis Program (RSAP). This study showed that the selection of culvert safety treatments should be flexible when considering different road and traffic characteristics. The findings demonstrated that culvert extension and grating were found to produce the lowest accident costs for all highway scenarios that were modeled, and guardrail protection was not recommended for any of the scenarios. Therefore, it is believed that the expanded adoption of culvert extension and culvert grates can improve overall highway safety.
\end{abstract}

Keywords: highway engineering, roadside safety, culverts, accidents, costs

\section{Problem Statement}

In the United States, approximately 40,000 lives are lost as a result of traffic fatalities every year. When considering the first harmful event, culverts and ditches account for more than $10 \%$ of the total fatal ran-off-road crashes across the country, according to the 2002 AASHTO Roadside Design Guide (RDG) (AASHTO 2002). The RDG also provides guidance regarding the adoption of safety measures used to reduce hazards created by roadside obstacles. The options, in order of preference, are to: (1) remove the obstacle; (2) redesign it; (3) relocate it; (4) reduce the impact severity by using appropriate devices; (5) shield the obstacle; and (6) delineate it. In accordance with these options, several research studies have been performed to investigate the viability of treatments for roadside culverts. The most commonly used safety alternatives have been: (1) relocating the culvert outside of the clear zone; (2) placing safety grates over the culvert; (3) shielding the culvert with guardrail; and (4) delineating the culvert with reflective object markers.

However, identifying the most appropriate safety treatment for roadside culverts has not been a simple task. Safety treatments do not always reduce the number of injuries and fatalities when compared to an untreated culvert. Unfortunately, relatively few studies have focused on developing guidelines for culvert treatments, and all of these studies are now outdated, such as the study conducted by Kohutek and Ross (1978). Thus, there is a need to evaluate all of the cul- vert safety treatments to determine the most appropriate design for each combination of highway and traffic characteristics. A safety evaluation of culvert treatment options should include an incremental benefit-to-cost ratio analysis. To conduct such an analysis, both benefits and direct costs need to be determined. Benefits may be determined in terms of accident cost reduction, whereas direct costs include installation, repair, and/or maintenance costs.

\section{Research Objective}

The primary objective of this study was to develop accident costs for a wide range of highway and traffic characteristics. The treatment alternative with the lowest accident cost was then classified as the "safest" over the available safety treatments.

Even though there could be different criteria to determine the "safest" treatment option, such as number of fatalities or number of serious injury accidents, it is believed that accident costs would be more appropriate because it incorporates the effects of all types of crashes. Further, since the cost of a fatal crash is many times higher than the cost of a serious injury crash, this high ratio between the cost of injury and fatal crashes should ensure that the lowest accident cost alternative will also be the lowest fatality option. Hence, presenting the safest treatment option recommendation findings based on accident costs is believed to be the most appropriate methodology. 


\section{Background}

According to the Fatality Accident Reporting System (FARS), two specific areas have been identified as the primary causes of fatal traffic accidents - roadside and intersection (FARS 2007). According to the FARS reports, over $70 \%$ of all fatalities occur either within roadside areas or at intersections. More than half of these fatalities were involved with roadway departure crashes. The RDG indicates that culverts and ditches alone have been responsible for approximately $12 \%$ of all traffic fatalities. Also, Zegeer et al. (1988) showed that culverts significantly affect the severity of run-off-roadway accidents.

Over the years, three safety treatments have been applied to roadside culverts, including extending the culvert hazard outside the clear zone, providing guardrail protection in front of the culvert, and covering the culvert opening with grating. Culvert extension involves relocating the culvert so that it may be located farther away from the edge of the traveled way to reduce the risk of vehicles striking the culvert. Culverts are normally extended to the edge of the clear zone. Guardrail protection involves determining a proper location and length of the guardrail so that errant vehicles are contained and redirected. Grating consists of placing steel grates over the culvert opening to allow errant vehicles to safely traverse the culvert opening.

Kohutek and Ross (1978) showed that, under certain circumstances, none of those safety treatments may be economically feasible. For some situations, guardrail installation was found to increase accident costs simply because the barrier is much longer and much closer to the roadway than a typical culvert and causes accident frequency to increase. Therefore, to minimize accident costs, the economic viability of safety treatments has to be verified. The economic viability of safety treatments may be checked by applying cost-effectiveness and/or benefit-to-cost ratio analyses methodologies to the proposed alternatives.

Several research studies have shown the efficacy of economical analyses on roadside safety improvement measures over the last four decades. Studies performed by Glennon (1974), Weaver et al. (1975), Campbell and Humphrey (1988), Zegeer et al. (1983), and Edwards et al. (1969) are some of the past studies which have demonstrated the applicability and usefulness of economic analyses in the transportation context. Edwards et al. (1969) developed the first encroachment probability model. This model was based on the encroachment data developed by Hutchinson and Kennedy (1966). In 1988, the Federal Highway Administration (FHWA) developed a model called the benefit-to-cost analysis program (BCAP) (FHWA 1988). Owing to much subjectivity on the inputs for crash and severity indexes, the BCAP was not well-received. Subsequently, FHWA developed ROADSIDE in 1994, which was a simplification of BCAP (FHWA 1994). Because several limitations were made, ROADSIDE did not result in a significant technical advancement of the benefit-to-cost ratio analysis procedures. Mak et al. (1998) developed a new cost-effectiveness procedure, known as the roadside safety analysis program (RSAP). RSAP has presented significant improvement in how encroachments and eventual crashes were assigned by adopting a stochastic solution method instead of a deterministic approach.

\section{Roadside Safety Analysis Program}

RSAP is an encroachment probability-based model that adopts a systematic approach composed of four modules. The encroachment module estimates average encroachment rate based on encroachment data developed by Cooper (1980). The encroachment rate is then multiplied by traffic volume to find encroachment frequency. RSAP adopts adjustment factors to control for horizontal and vertical alignments. The crash prediction module uses the information generated by the encroachment module to estimate crash frequency given an encroachment rate. The third module is the severity prediction module that primarily estimates the severity of a crash predicted by the crash prediction module. When combined, these three modules contain analysis procedures that allow the user to determine how many crashes would occur and their respective severities. The fourth module, a benefit/cost analysis module, converts all information gathered from the previous modules (i.e., number and severity of crashes) into accident costs. This process is completed by assigning accident cost to each accident severity level. For more details about RSAP, the reader should see Mak and Sicking (2003).

\section{Parametric Study}

A parametric study was undertaken to determine the sensitivity of accident costs to changes in input parameters. This process was intended to identify the highway and roadside characteristics that have the greatest impact on the benefits associated with the implementation of a culvert safety treatment. The roadway and roadside parameters found to be important to the estimation of accident costs would be candidates for inclusion in the final benefit estimation procedure, whereas parameters that proved to be less important would be omitted from the study.

The variables selected for inclusion in the parametric study are shown in Table 1 . After choosing the variables and selecting their values, a sensitivity analysis was conducted by running RSAP to analyze the impact of each variable on the change in accident cost. The importance of each parameter was then evaluated by changing it to its low, moderate, and high values, while values for all other parameters were held constant. By holding all other scenario characteristics constant, the variation in accident costs may be attributed to changes in the variable that has had its input values changed. Three values were assigned for each variable, with the exception of culvert type, for which five types were assigned.

The parametric study indicated that accident costs were found to go up whenever any of the following variables increased: slope steepness, average daily traffic, traffic growth rate, degree of horizontal curvature, culvert length, and culvert width. The opposite effect was observed for slope offset and culvert offset. In addition four variables, including number of lanes, lane width, culvert type, and slope depth were found to have a relatively limited effect on accident costs and were, therefore, eliminated from the remainder of the study.

Even though slope depth may be expected to significantly affect accident costs, it was eliminated because it was actually governed by changes in other variables such as slope steepness, culvert offset, and culvert width. Because the end of the culvert must be placed at the bottom of the slope, the total width of a slope should be equal to the sum of the culvert offset and width. Further, the depth of the slope equals its width divided by steepness. If the parametric study had been configured to isolate the effects of slope depth, this parameter would have been found to have an important effect on accident costs. Instead, the parametric study evaluated the importance of slope steepness and width.

Highway scenarios were then designed based on combinations of the seven variables that had a significant effect on accident cost. More details on the accident cost values generated from this sensitivity study may be found in the research report prepared by Albuquerque et al. (2009). 
Table 1. Roadway, Roadside, and Traffic Variables Used in the Parametric Study

\begin{tabular}{|c|c|c|c|c|c|c|c|c|c|}
\hline \multicolumn{10}{|c|}{ Variables with 3 values } \\
\hline $\begin{array}{l}\text { ADT } \\
\text { (veh./day) }\end{array}$ & $\begin{array}{l}\text { Traffic growth } \\
\text { factor (\%) }\end{array}$ & $\begin{array}{c}\text { Horizontal } \\
\text { curvature (degree) }\end{array}$ & $\begin{array}{l}\text { Culvert } \\
\text { size }(\mathrm{ft})\end{array}$ & $\begin{array}{c}\text { Slope } \\
\text { offset (ft) }\end{array}$ & $\begin{array}{c}\text { Slope } \\
\text { steepness }\end{array}$ & $\begin{array}{l}\text { Culvert } \\
\text { offset (ft) }\end{array}$ & $\begin{array}{c}\text { Slope } \\
\text { depth (ft) }\end{array}$ & $\begin{array}{l}\text { Lane } \\
\text { width (ft) }\end{array}$ & \# lanes \\
\hline $\begin{array}{l}950 \\
6,000 \\
12,000\end{array}$ & $\begin{array}{l}0 \\
2 \\
4\end{array}$ & $\begin{array}{l}0 \\
2 \\
4\end{array}$ & $\begin{array}{c}4 \times 6 \\
8 \times 10 \\
10 \times 12\end{array}$ & $\begin{array}{l}10 \\
12 \\
14\end{array}$ & $\begin{array}{l}2 \text { on } 1 \\
4 \text { on } 1 \\
6 \text { on } 1\end{array}$ & $\begin{array}{l}14 \\
16 \\
18\end{array}$ & $\begin{array}{l}10 \\
14 \\
20\end{array}$ & $\begin{array}{l}10 \\
11 \\
12\end{array}$ & $\begin{array}{c}2 \\
6 \\
10\end{array}$ \\
\hline
\end{tabular}

Culvert type

Rounded pipe culvert

Rounded pipe culvert with concrete rip-rap

Vertical end culvert

Box culvert with tangent wall

Box culvert with flared wall
Slope depth (ft)

10

11

12

14

20

\section{Safety Treatments}

Accident costs were predicted for a total of four safety treatment options. These options were: (1) leave the culvert unprotected, or do nothing; (2) extend the culvert outside of the clear zone; (3) shield the culvert with guardrail; and (4) place safety grates over the culvert. Note that there are some variations in the manner in which these safety treatment options could be implemented. To model these safety treatments using RSAP, procedures for implementing each alternative were adopted as described in subsequent sections.

\section{Do-Nothing}

The do-nothing option consisted of leaving the culvert opening untreated. Therefore, no changes to the original highway configuration were considered for the do-nothing option. The do-nothing option should only be considered when there is no benefit from adopting any other safety treatment. There is no direct cost associated with the do-nothing option.

\section{Culvert Extension}

Culvert extension was implemented while considering the clear zone concept. The clear zone may be defined as the unobstructed, relatively flat area on the roadside that is intended to provide errant drivers with the chance for recovery. The RDG recommends that clear zone width be selected based upon the design speed, average daily traffic, and sideslope steepness. According to the RDG, clear zone widths can be selected within a recommended range. In the present study, the average clear zone values were selected, that is, if the RDG recommends a clear zone range from 30 to $34 \mathrm{ft}$ (9 to $10.2 \mathrm{~m}$ ), the $32-\mathrm{ft}(9.6-\mathrm{m})$ average value was selected for use in the current study.

To design the culvert extension, the culvert was first extended to the edge of the clear zone. A flatter slope was then created, and it extended from the existing edge of the shoulder to the top of the culvert, as shown in Figure 1.

Unfortunately, RSAP is only able to model rectangular hazards, whereas the slopes associated with the culvert extension are triangular. Figure 1 represents a roadside culvert scenario where the slope depth is $9 \mathrm{ft}(2.74 \mathrm{~m})$, the culvert height is $8 \mathrm{ft}$ $(2.43 \mathrm{~m})$, and the culvert is placed $14 \mathrm{ft}(4.26 \mathrm{~m})$ from the upper slope break point. To model sideslope extension as triangular as possible, a series of rectangular hazards, or hazard mesh, were input into RSAP. A study was then undertaken to define

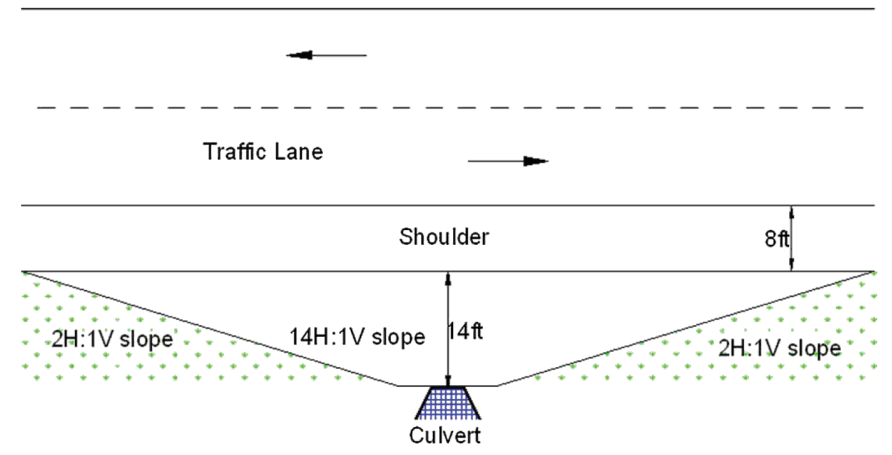

Figure 1. Triangular sideslope

the most appropriate mesh configuration that would be sufficient to make RSAP outputs relatively stable. The entire slope was divided into small rectangular hazards to create a "mesh". A series of slope models with various numbers of rectangular hazards was analyzed with one, two, three, four, and five rectangles. Figures 2 and 3 show scenarios with three and five rectangles, respectively. Accident costs were calculated using RSAP to evaluate changes in accident costs as the "mesh" was refined. This analysis revealed that accident costs increase as the number of rectangles was increased. This result may be attributed to the fact that the more rectangles the scenario has, the smaller the flattened sideslope area is. Even though more accurate accident costs would result from Figure 3 rather than from Figure 2, it was necessary to restrict the "mesh" to a reasonable number of rectangles to reduce modeling time. Also, accident costs were found to slightly increase for each added

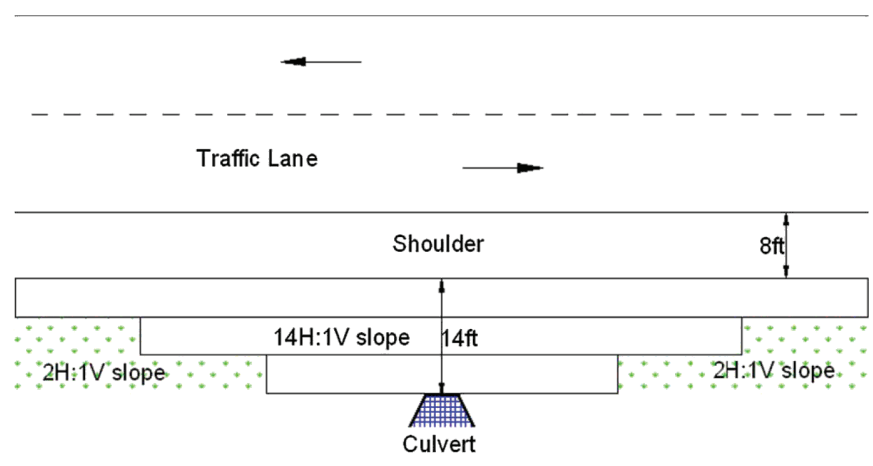

Figure 2. Sideslope divided into three rectangles 


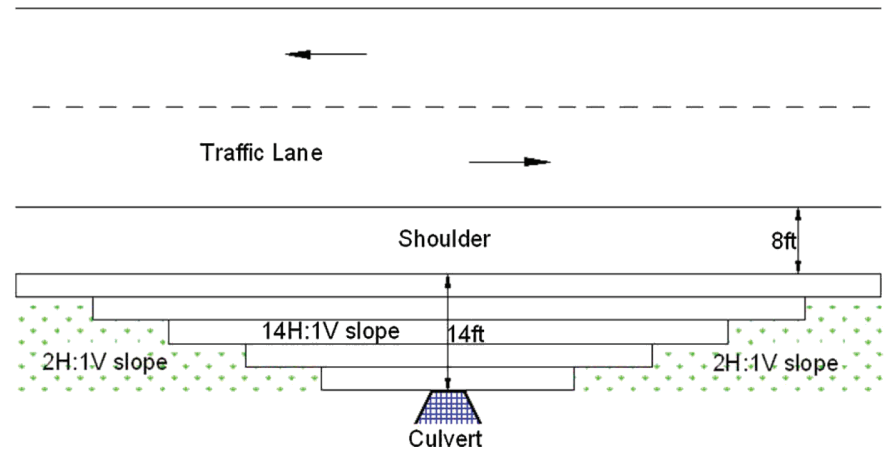

Figure 3. Sideslope divided into five rectangles

rectangle. Since the degree of sensitivity was found to be low and the RSAP runtimes decreased as the number of rectangle elements was reduced, three rectangles were utilized for each highway scenario.

\section{Guardrail Installation}

For guardrail installation, it was necessary to determine the optimum guardrail location and length for each class of roadway, roadside, and traffic characteristic. Guardrail location was determined by using the slope offset distance shown in Table 1. For example, if the slope offset is $10 \mathrm{ft}(3.04 \mathrm{~m})$, the front face of the guardrail should be no more than $8 \mathrm{ft}(2.43$ $\mathrm{m})$ from the travelway, considering that guardrail width is 2 $\mathrm{ft}(0.60 \mathrm{~m})$.

The 2002 and earlier AASHTO Roadside Design Guides present guidelines for determining guardrail length-of-need that was based on encroachment data obtained from a research study conducted by Hutchinson and Kennedy (1966). The encroachment data was used to estimate how far errant vehicles could be expected to travel behind a guardrail before slowing or coming to a stop. For the purposes of developing design guidelines, guardrail geometry was configured to capture the 85th percentile encroachment length. However, more recent research conducted by Cooper (1980) found much shorter travel distances. Wolford and Sicking (1996) developed guardrail runout length guidelines using data from Cooper (1980). These revised guidelines recommended much shorter guardrails.

Coon et al. (2006) compared the two different guardrail length recommendations with real-world crash data and found that the shorter guardrail lengths produced by the Cooper data would result in the capture of more than $90 \%$ of all encroaching vehicles. As a result, AASHTO's Technical Committee on Roadside Safety (TCRS) adopted the shorter guardrail length guidelines based on Cooper for inclusion in the new edition of the Roadside Design Guide that is currently under development. Therefore, guardrail length guidelines developed by Wolford and Sicking (1996) that were based on Cooper's data were selected for use in the study described herein.

Guardrail length-of-need was calculated based on the methodology used by the RDG as shown in the following equation:

$$
x=\frac{L_{a}+(b / a)\left(L_{1}\right)-L_{2}}{(b / a)+\left(L_{d} / L_{a}\right)}
$$

where $b / a=$ flare rate; $L_{1}=$ tangent length of barrier upstream from the hazard; $L_{2}=$ lateral distance from the edge of the traveled way; $L_{a}=$ distance from the traveled way edge to the back of the hazard; and $L_{r}=$ guardrail runout length.

In Equation (1), flare rates were considered. Guardrail flare rates are used to decrease accident frequency as the guardrail installation becomes farther away from the roadway and to decrease costs by adopting shorter guardrail systems. However, guardrail systems cannot be safely flared onto steep roadside slopes. Thus, guardrail use was restricted to tangent installations because the slopes used in this study were not sufficiently flat to allow for the use of flared guardrail installations. When the flare rate is removed from Equation (1), the formula for guardrail length-of-need becomes

$$
x=\frac{L_{a}-L_{2}}{L_{a} / L_{r}}
$$

Equation (2) was used for the determination of both upstream and downstream guardrail lengths. The only difference between the upstream and downstream calculation is the $L_{a}$-value. Since $L_{a}$ corresponds to the distance between the edge of the traveled way and the back of the roadside hazard, one lane width (12 ft or $3.6 \mathrm{~m})$, corresponding to the opposing lane, was added to the $L_{a}$ distance when calculating downstream or opposing traffic guardrail for two-lane roadways. The guardrail runout length, developed by Wolford and Sicking (1996), is the theoretical distance needed for most errant vehicles that leave the roadway to come to a stop. A test level 3 (TL-3) W-beam guardrail system was selected for use in this study because it represents the most widely used barrier system across the nation. TL-3 guardrail end-terminals were also used so that the entire guardrail installation would comprise a system meeting current impact safety standards.

\section{Grating}

Safety grates are applied to culvert openings to make the hazards traversable. Ross et al. (1982) and Polivka et al. (2007) have shown that grating is a feasible and effective safety treatment for roadside culvert openings. Grating has been defined as the fourth treatment alternative for this study. To implement this treatment option, different procedures were adopted depending upon steepness of the roadside slope.

Polivka et al. (2007) tested and approved safety grates for use on slopes as steep as $3 \mathrm{H}: 1 \mathrm{~V}$. Thus, if a roadside condition contained $3 H: 1 \mathrm{~V}$ or flatter roadside slopes, the safety grates could be placed on the top of the culvert opening without altering the roadside slope. Note that Polivka et al. (2007) conducted full-scale crash testing that showed that grates did not greatly increase the risk of occupant injury. Therefore, a grated culvert was assigned the same severity as the slope upon which it was installed. On the other hand, when a scenario contained roadside slopes steeper than $3 H: 1 \mathrm{~V}$, the entire slope had to be flattened to $3 H: 1 \mathrm{~V}$ to accommodate the safety grates because it is believed that rollover propensity is too high on sideslopes steeper than $3 H: 1 \mathrm{~V}$.

\section{Accident Cost Prediction}

Roadway, roadside, and traffic characteristics found to be important for the RSAP parametric study were then utilized to develop a matrix of roadway and roadside conditions to be analyzed within the study. Table 2 shows the seven variables selected for inclusion in the accident cost analysis, and it presents the variations in each variable included in the study. Note that Table 2 indicates that some of the variables did not have 
Table 2. Road and Traffic Characteristics Used in the Main Study Analysis

\begin{tabular}{|c|c|c|c|c|c|c|}
\hline \multicolumn{7}{|c|}{ Local highway class } \\
\hline Slope steepness & TGF (\%) & Curvature (degree) & Culvert size (ft) & Slope offset (ft) & Culvert offset (ft) & ADT (veh./day) \\
\hline $\begin{array}{l}2 \text { on } 1 \\
4 \text { on } 1\end{array}$ & $\begin{array}{l}0 \\
3\end{array}$ & $\begin{array}{c}0 \\
5 \\
10\end{array}$ & $\begin{array}{c}4 \times 6 \\
8 \times 10 \\
10 \times 12\end{array}$ & $\begin{array}{c}2 \\
6 \\
10\end{array}$ & $\begin{array}{c}4 \\
10 \\
16\end{array}$ & $\begin{array}{c}200 \\
400 \\
800 \\
1,600 \\
3,000\end{array}$ \\
\hline
\end{tabular}

\begin{tabular}{lcccccc}
\hline \multicolumn{5}{c}{ Rural arterial highway class } \\
\hline Slope steepness & TGF (\%) & Curvature (degree) & Culvert size (ft) & Slope offset (ft) & Culvert offset (ft) & ADT (veh./day) \\
2 on 1 & 0 & 0 & $4 \times 6$ & 8 & 10 & 1,000 \\
4 on 1 & 3 & 3 & $8 \times 10$ & 14 & 18 & 2,000 \\
& & 6 & $10 \times 12$ & 20 & 26 & 4,000
\end{tabular}

8,000

12,000

\begin{tabular}{|c|c|c|c|c|c|c|}
\hline \multicolumn{7}{|c|}{ Freeway highway class } \\
\hline Slope steepness & TGF (\%) & Curvature (degree) & Culvert size $(\mathrm{ft})$ & Slope offset (ft) & Culvert offset (ft) & ADT (veh./day) \\
\hline $\begin{array}{l}2 \text { on } 1 \\
4 \text { on } 1 \\
6 \text { on } 1\end{array}$ & $\begin{array}{l}0 \\
3\end{array}$ & $\begin{array}{l}0 \\
2 \\
4\end{array}$ & $\begin{array}{c}4 \times 6 \\
8 \times 10 \\
10 \times 12\end{array}$ & $\begin{array}{l}8 \\
16 \\
24\end{array}$ & $\begin{array}{l}10 \\
18 \\
26\end{array}$ & $\begin{array}{c}5,000 \\
25,000 \\
50,000 \\
100,000\end{array}$ \\
\hline
\end{tabular}

as many variations as others. For example, there are just two values for the traffic growth factor, whereas there are five values for the average daily traffic for most highway classes. Parameter variations were dependent upon highway functional class and were selected to cover the reasonable range of variation in each parameter.

The variables shown in Table 2 were used to model more than 3,000 highway scenarios in RSAP. Over 1,000 scenarios were created for each highway class. Variable values were assigned to characterize each highway functional class. For instance, since local roads have low mobility and are designed primarily to provide land access, shorter hazard offsets, sharper horizontal alignments, and steeper slopes were selected to reflect lower safety standards. On the other hand, since freeways are considered high-speed and high-volume arterials, much higher traffic volumes as well as higher safety standards (such as flatter curves and sideslopes) were selected to reflect higher design standards used on freeways.

Accident costs were determined from the RSAP modeling process and were reported by Albuquerque et al. (2009). These predicted costs were then used to determine the benefit (i.e., accident cost reduction) of applying each culvert safety treatment to any particular highway scenario.

To determine accident costs, RSAP attributes dollar amounts to five different accident injury levels: $\$ 2,600,000$ to fatal injury; $\$ 180,000$ to severe injury; $\$ 36,000$ to moderate injury; $\$ 19,000$ to minor injury; and $\$ 2,000$ to property damage only. These accident costs correspond to the FHWA Comprehensive Costs. These accident costs were developed by Miller et al. (1991), and they include direct costs as well as indirect costs, such as the costs of pain, suffering, and reductions in quality of life.

\section{Findings}

From the analysis, five decision-making graphs were prepared to aid in the determination of culvert safety treatments for different roadway classes as well as for different combinations of road and traffic characteristics. As depicted in Figure
4, each graph shows the culvert safety treatment that produces the lowest accident cost for each highway scenario. Extending the culvert or installing safety grates were found to provide the lowest crash costs for every highway scenario that was studied.

As shown in Figure 4(a), safety grating was found to produce the lowest accident cost on local roads with $2 \mathrm{H}: 1 \mathrm{~V}$ sideslopes. On the other hand, culvert extension was found to be the safest treatment on local road scenarios with $4 \mathrm{H}: 1 \mathrm{~V}$ sideslopes combined with larger culverts and average daily traffic of 800 or more, as shown in Figure 4(b). Figures 4(c) and 4(d) provide results for rural arterial highways. Figure 4(c) shows that culvert extension was found to produce the lowest accident cost on curved roads with $4 \mathrm{H}: 1 \mathrm{~V}$ sideslopes, with a slope offset distance of $8 \mathrm{ft}(2.43 \mathrm{~m})$, and an average daily traffic volume higher than 1,000. Figure 4(d) indicates that the use of safety grates produced the lowest accident cost for any other road scenario not addressed by Figure 4(c). Ultimately, Figure 4(e) shows that the installation of safety grates is the safest treatment for all freeway scenarios.

Even though these five decision-making graphs may be helpful in addressing which safety treatment presents the lowest accident cost given a group of roadway and traffic characteristics, they do not allow comparisons of accident costs among the four safety treatments because accident cost values are not presented. However, it is important to note that presenting the accident costs in any sort of plot is not practical in this case because of the large number of scenarios modeled (i.e., $>3,000$ ) and also because of the large number of variables used to characterize each scenario. Each scenario was constructed based on seven variables, and displaying findings in function of that many variables in any sort of plot would require a large number of figures. Therefore, it is believed that the best manner of effectively showing the accident costs is in a tabulation format, as shown in Table 3. Table 3 shows some of the accident costs developed for freeways with straight sections, average daily traffic equal to 25,000, and a traffic growth factor equal to zero. Note that, for these roadway and traffic characteristics, Table 3 indicates that grating presents the low- 


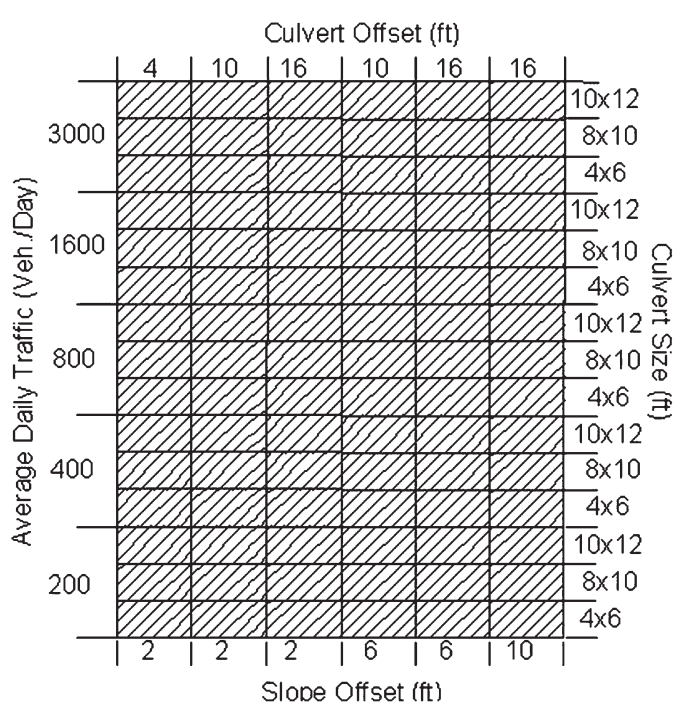

(a)

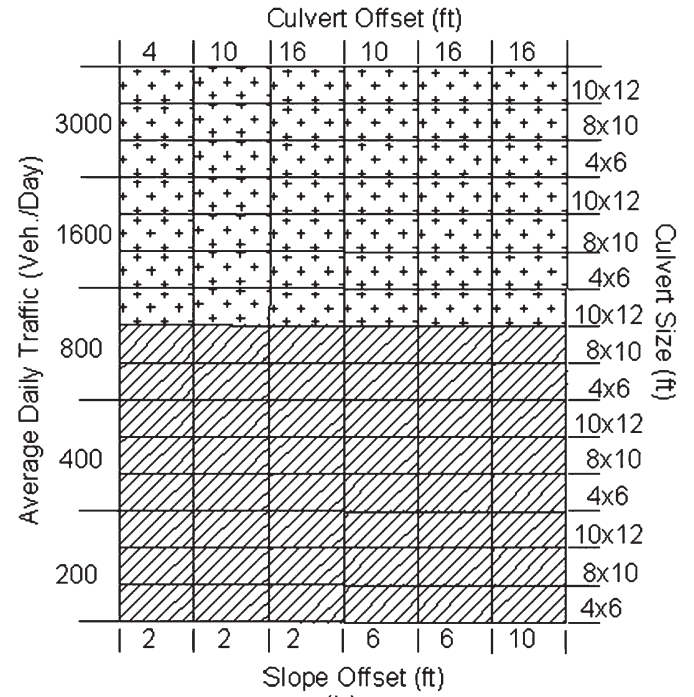

(b)

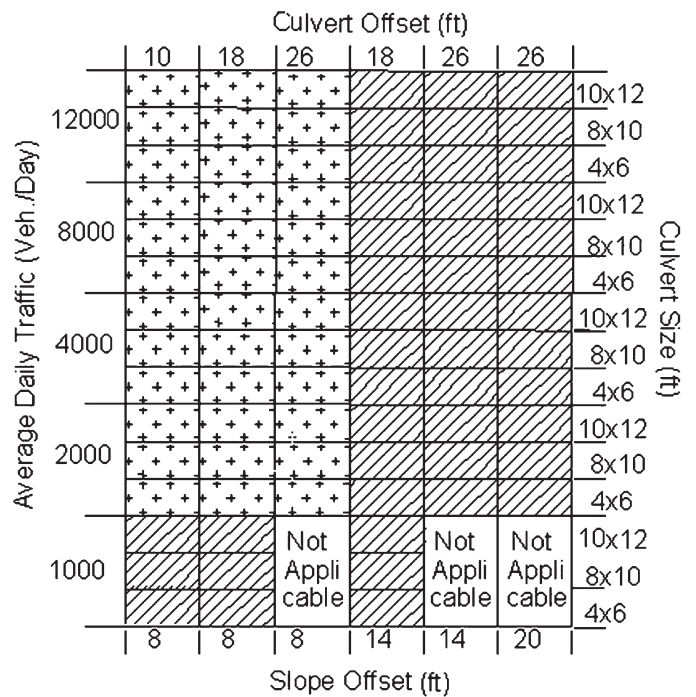

(c)

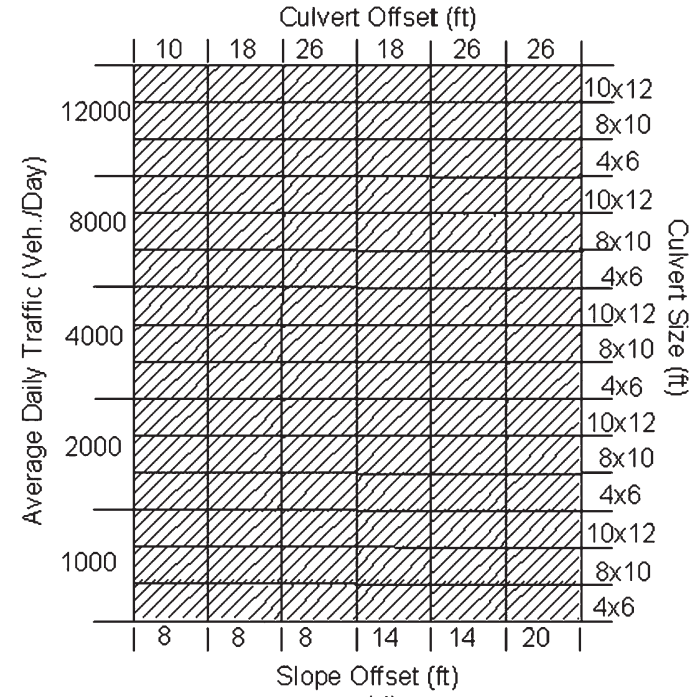

(d)

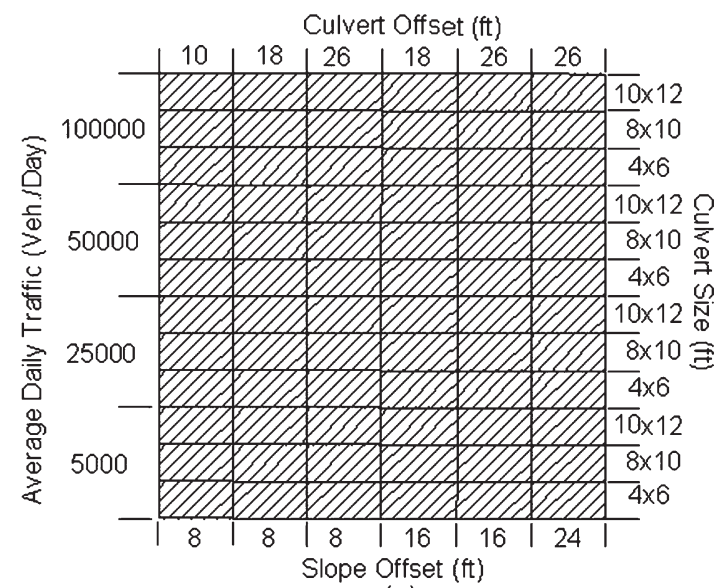

(e)
Legend:

Extend the Culvert Grating

Figure 4. Safety options based on lowest accident cost for: (a) local road with 2H:1V sideslopes; (b) local road for all other scenarios; (c) rural arterial with curved sections and 4H:1V sideslopes; (d) rural arterial for all other scenarios; (e) freeway 
Table 3. Accident Costs for Freeways

\begin{tabular}{|c|c|c|c|c|c|c|c|c|}
\hline $\begin{array}{l}\text { Culvert } \\
\text { size }(\mathrm{ft})\end{array}$ & $\begin{array}{r}\text { Slope } \\
\text { steepness }\end{array}$ & $\begin{array}{r}\text { Slope } \\
\text { offset (ft) }\end{array}$ & $\begin{array}{r}\text { Culvert } \\
\text { offset (ft) }\end{array}$ & $\begin{array}{r}\text { Slope } \\
\text { depth }(\mathrm{ft})\end{array}$ & $\begin{array}{l}\text { Do-nothing } \\
\text { acc. cost }(\$)\end{array}$ & $\begin{array}{r}\text { Culvert extension } \\
\text { acc. cost }(\$)\end{array}$ & $\begin{array}{r}\text { Guardrail installation } \\
\text { acc. cost }(\$)\end{array}$ & $\begin{array}{r}\text { Grating } \\
\text { acc. cost }(\$)\end{array}$ \\
\hline \multirow[t]{9}{*}{$4 \times 6$} & 2 on 1 & 8 & 10 & 5 & 38,409 & 33,274 & 33,302 & 14,772 \\
\hline & & & 26 & 13 & 46,222 & 39,458 & 39,808 & 17,666 \\
\hline & & 16 & 18 & 5 & 27,586 & 25,931 & 24,649 & 10,569 \\
\hline & & & 26 & 9 & 28,699 & 26,207 & 25,272 & 11,041 \\
\hline & & & 18 & 6.5 & 11,530 & 9,193 & 9,441 & 5,482 \\
\hline & & & 26 & 8.5 & 10,622 & 8,424 & 9,848 & 5,589 \\
\hline & & 16 & 18 & 4.5 & 8,783 & 7,032 & 6,009 & 3,831 \\
\hline & & & 26 & 6.5 & 8,215 & 6,800 & 6,720 & 3,938 \\
\hline & & 24 & 26 & 4.5 & 6,135 & 4,931 & 4,557 & 2,765 \\
\hline \multirow{8}{*}{$8 \times 10$} & & & 26 & 13 & 35,345 & 33,844 & 30,210 & 12,655 \\
\hline & & 24 & 26 & 9 & 23,485 & 22,073 & 19,833 & 8,396 \\
\hline & 4 on 1 & 8 & 10 & 8.5 & 18,397 & 10,274 & 11,691 & 5,589 \\
\hline & & & 18 & 10.5 & 14,155 & 11,842 & 12,699 & 5,669 \\
\hline & & & 26 & 12.5 & 15,363 & 13,174 & 13,254 & 5,709 \\
\hline & & 16 & 18 & 8.5 & 13,334 & 11,433 & 8,471 & 4,018 \\
\hline & & & 26 & 10.5 & 12,326 & 9,826 & 9,372 & 4,058 \\
\hline & & 24 & 26 & 8.5 & 10,091 & 8,591 & 6,451 & 3,043 \\
\hline
\end{tabular}

est accident costs, as depicted in Figure 4. Any other accident cost values not shown in Table 3 are available in a report by Albuquerque et al. (2009).

\section{Summary and Conclusions}

The purpose of this study was to identify the "safest" treatments for roadside culverts for a wide range of highway, traffic, and roadside conditions. Guidelines were developed based on accident costs that were associated with various road and traffic conditions. These accident costs were estimated by using an encroachment probability model and were reported by Albuquerque et al. (2009). Using the accident costs, the benefits can be quantified according to the desired safety treatment option. These benefits can be used to determine benefit-to-cost ratios, once the direct costs (i.e., installation, repair, and maintenance costs) associated with each treatment option have been found. Ultimately, these benefit-to-cost ratios may allow highway designers to make better decisions regarding the most appropriate safety treatment for roadside cross-drainage culverts under a great variety of road and traffic conditions.

The study began with a parametric study that investigated road and traffic characteristics that have significant impacts on accident cost. Eleven variables were initially utilized, and four variables were found to not impact accident costs much. The variables may be found in Tables 1 and 2. As a result, these four variables were eliminated from further analysis. The remaining seven variables were used to analyze different highway scenarios using three highway classes. Values were assigned to the variables based on highway functional class.

Subsequently, procedures were implemented to implement safety treatments using RSAP. These procedures were implemented based either on information from the RDG or on find- ings from relevant literature. Accident costs were then determined for each combination of road and traffic variables, as well as for each of the four safety treatments.

The research results are presented in Figure 4 and provide guidance on identifying the most appropriate safety treatment for roadside cross-drainage culverts. It should be noted that guardrail installation was not found to provide the lowest accident cost for any highway scenario. Even though guardrail protection has been widely used to shield motorists from culvert openings, it was not found to be the safest option under any circumstance. Safety grates produced the lowest accident cost in most instances, mainly in scenarios which involved very steep sideslopes (i.e., $2 \mathrm{H}: 1 \mathrm{~V}$ slopes). Culvert extension produced the lowest accident cost on local roads with average daily traffic not less than 800 , as well as on rural arterials with a slope offset of $8 \mathrm{ft}$ and average daily traffic not less than 2,000. Overall, safety grates were found to be the safest treatment for most scenarios within the three noted highway classes. In fact, safety grating was found to be the safest treatment on freeways. These findings indicate that the choice of culvert safety treatments must be flexible to road and traffic characteristics and that the expanded use of culvert extension and grating produce safer roadsides.

It is also important to stress that these findings are based on accident costs, which means that if guardrail protection was not found to be the safest option in any case, this study does not suggest that guardrail should never be used. This study presented the safest treatment option, but direct costs associated with implementation of each safety treatment option should also be considered. Ultimately, decisions should be based on the economic viability of each safety treatment implemented, which means that the most appropriate treatment option should be the one that produces the highest benefit 
(i.e., accident cost reduction) for every dollar invested.

\section{Limitations}

Even though RSAP has been widely accepted by the transportation community as an innovative and capable tool, it still has some limitations that need to be addressed in the near future. For example, RSAP does not take into account the effect of weather, vehicle performance, and driving behavior during encroachments, which may be attributed to the lack of reliable data. Also, because RSAP uses encroachment data developed by Cooper (1980) in Canada, the encroachment frequency and extent may not exactly reflect the encroachment pattern seen throughout the United States' roadways owing to differences in factors such as traffic, roadway, weather, and vehicle fleet.

Acknowledgments - The writers wish to acknowledge the Iowa Department of Transportation for funding this study.

\section{References}

AASHTO. (2002). Roadside design guide, Washington, DC.

Albuquerque, F. D. B., Sicking, D. L., and Lechtenberg, K. A. (2009). "Evaluation of safety treatments for roadside culverts." Midwest Research Rep. No. TRP-03-201-09, Midwest Roadside Safety Facility, University of Nebraska-Lincoln, Lincoln, NE.

Campbell, B., and Humphrey, T. F. (1988). "Methods of cost-effectiveness analysis for highway projects." NCHRP Synthesis of Highway Practice No. 142, Transportation Research Board, Washington, DC.

Coon, B. A., Sicking, D. L., and Mak, K. K. (2006). “Guardrail runout length design procedures revisited." Transp. Res. Rec., 1984, 14-20.

Cooper, P. (1980). “Analysis of roadside encroachments: Single vehicle run-off accident data analysis for five provinces." British Columbia Research Council, Vancouver, BC, Canada.

Edwards, T. C., Martinez, J. E., McFarland, W. E., and Ross, H. E. (1969). "Development of design criteria for safer luminaire supports." NCHRP Rep. No. 77, AASHTO, Washington, DC.

Fatal Accident Reporting System (FARS). (2007). National Highway Traffic Safety Administration (NHTSA), Washington, DC.

Federal Highway Administration (FHWA). (1988). “Benefit to cost analysis program." Publ. No. FHWA-TS-88, Turner-Fairbank Highway Research Center, McLean, VA.
Federal Highway Administration (FHWA) . (1994). "ROADSIDE," McTrans Center, University of Florida, Gainesville, FL. Glennon, J. C. (1974). "Roadside safety improvement programs on

freeways - A cost-effective priority approach." NCHRP Rep. No. 148, Transportation Research Board, Washington, DC.

Hutchinson, J. W., and Kennedy, T. W. (1966). “Medians of divided highways - Frequency and nature of vehicle encroachments." Engineering Experiment Station Bulletin No. 487, University of Illinois, Urbana-Champaign, IL.

Kohutek, T. L., and Ross, H. E. (1978). "Safety treatment of roadside culverts on low volume roads." Rep. No. FHWA-TX-77-225-1, Texas Transportation Institute, College Station, TX.

Mak, K. K., and Sicking, D. L. (2003). “Roadside safety analysis program (RSAP) - Engineer's manual." NCHRP Rep. No. 492, Transportation Research Board, Washington, DC.

Mak, K. K., Sicking, D. L., and Zimmerman, K. (1998). "Roadside safety analysis program: A cost-effectiveness analysis procedure." Transp. Res. Rec., 1647, 67-74.

Miller, T., Blomquist, G., Dillingham, A., Douglass, J., Gellert, W., and Pindus, N. (1991). "The costs of highway crashes." Rep. No. FHWA-RD-91-055, Federal Highway Administration, Washington, DC.

Polivka, K. A., Sicking, D. L., Reid, J. D., Bielenberg, B. W., Faller, R. K., and Rohde, J. R. (2007). "Performance evaluation of safety grates for cross drainage culverts." Transportation Research Rep. No. TRP-03- 196-07, Midwest Roadside Safety Facility, University of Nebraska-Lincoln, Lincoln, NE.

Ross, H. E., Jr., et al. (1982). "Safety treatment of roadside drainage structures." Transp. Res. Rec., 868, 1-12.

Weaver, G. D., Post, E. R., and Woods, D. L. (1975). “Cost-effectiveness analysis of roadside safety improvements." Transp. Res. Rec., $543,1-15$.

Wolford, D., and Sicking, D. L. (1996). “Guardrail runout lengths revisited." Transportation Research Record, 1528, 78-86.

Zegeer, C. V., Parker, M. R., and Goodell-Grivas, I. (1983). “Cost-effectiveness of countermeasures for utility pole accidents." Rep. No. FHWA/RD-83/063, Federal Highway Administration, Washington, DC.

Zegeer, C. V., Reinfurt, D. W., Hunter, W. W., Hummer, J., Stewart, R., and Herf, L. (1988). "Accident effects of sideslope and other roadside features on two-lane roads." Transp. Res. Rec., 1195, 33-47. 